\title{
La recepción de Bentham en la Nueva Granada
}

\section{The acceptance of Bentham in the New Kingdom of Granada}

\author{
Lisímaco Parra \\ liparraparis@gmail.com \\ Universidad Nacional de Colombia \\ Fecha de recepción 25 de febrero de 2014 \\ Fecha de aceptación 25 de abril de 2014
}

Pues no hay tal Finis ultimus [fin último], ni Summum Bonum [bien sumo] como se dice en los libros de los filósofos de la vieja moral. [...] La felicidad es un progreso continuo del deseo, de un objeto a otro, en donde alcanzar el primero es siempre el camino para el siguiente. La causa de esto es que el objeto del deseo del hombre no es disfrutar solamente una vez y por un instante de tiempo, sino asegurar el camino de su deseo futuro. (Hobbes, $\mathrm{XI}, 1$, 1994, p. 57)

\section{Resumen}

Tomando como punto de referencia central la disputa entre los diarios El Constitucional de Popayán y El Constitucional de Cundinamarca (1835-1836), el presente artículo intenta comprender las dificultades de la recepción neogranadina de las doctrinas utilitaristas de Jeremías Bentham. La principal de ellas residiría en la inconmensurabilidad entre los presupuestos lógicos sustancialistas subyacentes en los receptores - no importa si partidarios o impugnadores del utilitarismo-, y la lógica funcionalista que presuponen los planteamientos de Bentham. Los conceptos de substancia y de función se explican recurriendo a un reconocido trabajo de Ernst Cassirer. En su conjunto, las élites criollas, forzadas heterónomamente a la Independencia, estarían básicamente satisfechas con la lógica sustancialista. Solo en virtud de las exigencias derivadas del intercambio con unos interlocutores europeos nuevos, parte de ellas se habría interesado en aprender los códigos utilitaristas, no obstante sin ahondar hasta sus supuestos lógicos funcionalistas. 
Palabras clave: Bentham, Nueva Granada, substancia, función, utilitarismo.

Códigos JEL: B12, I31, R13.

\begin{abstract}
Taking as a point of reference the dispute between the newspapers El Constitucional de Popayán and El Constitucional de Cundinamarca (1835-1836), this article seeks to understand the difficulties found in the reception of Bentham's utilitarian doctrines in Nueva Granada. The main obstacle lies in the incommensurability between presuppositions of a substantialist logical nature held by the receptors - no matter whether followers or detractors of utilitarianism-, and the logical functionalism underlying Bentham's claims. The concepts of substance and function are explained by appealing to a well-known work by Ernst Cassirer. In general, it can be said that the "criollo" elites, forced from without to achieve their independence, were rather satisfied with their underlying substantialist logic. It was only due to exigencies derived from their exchange with new European interlocutors, that part of these elites eventually became interested in learning the utilitarian codes, not yet delving into their functionalist logical underpinnings.
\end{abstract}

Keywords: Bentham, New Granada, substance, function, utilitarianism

JEL Codes: B12, I31, R13 


\section{Planteamiento del problema}

Los estudios dedicados al tema de la recepción de las ideas utilitaristas en la Nueva Granada coinciden en señalar el carácter "ecléctico" de tal recepción: "si eran cualquier cosa, los granadinos eran eclécticos" (Gilmore, 1995, vol. 1, p. 146). Se alude con ello al intento de conciliación de doctrinas, acaso verosímiles, pero de procedencias diversas y con consecuencias contradictorias; pero además, tal intento no estaría guiado por pedanterías teóricas, sino por la urgencia de resolver problemas "prácticos"."

En la accidentada legislación que acompañó la recepción neogranadina de Jeremías Bentham pueden encontrarse varios ejemplos de esta actitud ecléctica. Como se sabe, en el decreto del 8 de noviembre de 1825, el vicepresidente de la República encargado del poder ejecutivo, general Francisco de Paula Santander, decretó la enseñanza obligatoria en colegios mayores y universidades del derecho público según los principios de Bentham. A su regreso de la campaña del Perú, en 1827, Bolívar reasumió la Presidencia, se hizo a poderes dictatoriales (agosto de 1828), fue víctima de un atentado (25 de septiembre de 1828) imputado a jóvenes intelectuales benthamistas, y prohibió entonces la enseñanza de Bentham (20 de octubre de 1828). Santander fue desterrado. Tras su regreso, después de la muerte de Bolívar, el entonces presidente Santander, con la ley 30 de mayo de 1835, reinstauró la obligatoriedad de la enseñanza de los tratados de legislación de Bentham. La reacción conservadora antibenthamista no se hizo esperar. Lino de Pombo, secretario de Santander, se pronunció al respecto en los siguientes términos: "los tratados de Bentham, particularmente los de legislación civil y penal, admirables por el espíritu de análisis con que están escritos, y por lo luminoso y profundo de sus doctrinas, ilustran el entendimiento". Continúa afirmando que "nada hay en dichos tratados de legislación civil y penal que leído con meditación y bien comprendido pueda ser perjudicial y alarmante". No obstante, para tranquilizar a los adversarios anuncia que mientras se encuentra un autor idóneo distinto a Bentham para la enseñanza, los profesores habrán de ser escrupulosamente cuidadosos, "explicando las doctrinas y proposiciones de Jeremías Bentham, de modo que ellas no se sobrepongan a las leyes que prescriben la enseñanza de moral y derecho natural [...], y declaran una protección especial a la religión revelada. Por consiguiente, no podrán enseñarse, ni menos sostenerse en dictámenes públicos, principios contrarios a tales disposiciones" (López, 1993, pp. 108-110).

Podría ser que razones de cálculo político obligaron a conceder que eventualmente pueden presentarse contradicciones entre la doctrina utilitarista y la moral, la ley natural o el catolicismo; no obstante, se presume que el conflicto no afectará la esencia misma del utilitarismo, y de ahí que se creyera que podía mutilárselo en aspectos puntuales polémicos, sin que ello fuera en detrimento ni de su núcleo fundamental, ni de la fe católica.

La calificación de eclecticismo para la recepción neogranadina del utilitarismo, repetida una y otra vez, parece entonces correcta. No obstante me parece insuficiente: al fin y al cabo, es probable que, al menos en algún momento de su génesis, toda recepción de ideas haya tenido toques eclécticos. Pero además, la calificación es a menudo expresada con tintes elogiosos: los criollos neogranadinos no eran ratones de biblioteca sino hombres de acción; no estaban interesados en la coherencia de las premisas teóricas, sino en la solución de problemas

1 Al respecto, véase Morse (1982), pp. 91-93; Marquínez (1983), p. 13; Posada Carbó (2011), p. 163. 
prácticos. Por mi parte, pienso que aunque las incoherencias teóricas puedan ser ocasión de fastidio o de regocijo para la pedantería sistemática, lo que aquí importa es si ellas expresan características existenciales, y también intereses, que, por supuesto, tienen consecuencias prácticas. Es bajo esta luz que quiero examinar las eventuales "carencias" exegéticas.

Así pues, quiero intentar ir más allá de la mera calificación del fenómeno como "eclecticismo", para "escarbar" en él, si es posible, algunas determinaciones adicionales. Y en esta exploración reconozco mi deuda con la producción investigativa de un grupo de intelectuales, en su mayor parte norteamericanos, que ya desde el decenio de los sesenta y hasta bien entrado los ochenta del siglo pasado caracterizaron a Iberoamérica, al compararla con la anglosajona, como la "tradición distinta". Autores como Richard M. Morse, Glen Caudill Dealy, Woodrow Borah (1963) o Howard Wiarda (1982) plantearon sugestivas preguntas. Que algún otro haya pretendido responderlas mediante su adhesión a "dictaduras de cementerio" — la expresión es de Morse - , o mediante una no muy convincente amalgama - iotra vez el eclecticismo! - entre Escuela de Frankfurt y tradición ibero-católica - como es el caso del propio Morse-, no quita pertinencia a esas preguntas. Me siguen resultando misteriosas las causas de la completa ignorancia de esta discusión en el ámbito colombiano. ${ }^{2}$

\section{La lógica del utilitarismo}

Creo que tras las doctrinas políticas del liberalismo en general, y del utilitarismo en particular, existe una "lógica" que les sirve de sustento; prescindiendo de ella, dichas doctrinas pierden coherencia o resultan difícilmente inteligibles. Quiero pues, en primer lugar, esbozar algunos de los trazos centrales de dicha lógica.

En un importante estudio publicado en 1910, Ernst Cassirer esbozó el complejo camino que va de la lógica aristotélica de la substancia a la lógica de la función. Pese a que la culminación de este proceso solo se da en el siglo XX, quiero afirmar que la filosofía benthamiana, y particularmente su antropología, se entienden cabalmente teniendo en mente el concepto de función. Por su parte, tanto los partidarios como los detractores neogranadinos del utilitarismo de Bentham solo pudieron alinearse en el campo que les era más familiar, a saber, el del concepto de substancia ${ }^{3}$. Quizás podamos encontrar en este no desplazamiento lógico la causa del "eclecticismo" criollo.

2 La única referencia que encuentro es una reseña de Eduardo Posada Carbó, publicada en 1994, del libro de Dealy The Latin Americans. Spirit and ethos. Aunque no sin aciertos en su crítica, parecería que Posada se deja arrastrar por sus humores. El resultado es una reseña tan unilateral como la unilateralidad por él criticada en Dealy, y por supuesto que francamente insuficiente como evaluación de las propuestas de Dealy. Véase la nota de Posada en http://www.eltiempo.com/archivo/documento/MAM-5775

3 El texto de Cassirer, Substanzbegriff und Funktionsbegriff. Untersuchungen über die Grundfragen der Erkenntniskritik, ha sido traducido al inglés, al francés y al italiano. Por lo visto, en español creemos poder prescindir de él. La contraposición entre los conceptos de substancia y función también ha sido aplicada al esclarecimiento de la relación entre la obra de Carl Schmitt y la de Hans Kelsen. Es cierto que en este último caso, se trata de autores, tiempos y espacios distintos a los que aquí nos ocupan. Con todo, la relación temática podría ser más estrecha que lo que a simple vista parecería. Al respecto, véase el penetrante estudio de Raphael Gross (1999) reseñado en las referencias. 
De la rica y detallada exposición de Cassirer quiero resaltar de manera muy somera tres puntos. En primer lugar, un presupuesto central de la lógica aristotélica es que "el concepto no es un esquema meramente subjetivo en el que agrupamos los elementos comunes de un grupo dado de cosas" (Cassirer, 1994, p. 9). Aunque es un producto abstraído, "al mismo tiempo es la forma real que garantiza la conexión causal y teleológica de las cosas individuales". De esta manera, se supone que tanto el concepto en su configuración, como la definición - por género y especie- de un objeto, se acoplan a las relaciones fundamentales de la realidad.

Por lo anterior, podemos entender la persistente predominancia del concepto de substancia: las puras formas lógicas siempre se entienden como concatenadas con el referente sustancial: "el sistema completo de las definiciones científicas sería al mismo tiempo la expresión completa de las fuerzas substanciales que dominan la realidad" (Cassirer, 1994, p. 9). En síntesis, la teoría tradicional sobre los conceptos presupone la inmanencia de los mismos en la realidad.

El segundo punto se refiere a la limitación del concepto de substancia cuando se trata del conocimiento de los individuales: individuum est ineffabile. En efecto, frente a la multiplicidad sensible, el entendimiento reflexiona (es decir, compara y diferencia), y luego abstrae, es decir, resalta, limpios de mezclas e impurezas adheridas, los trazos esenciales en que coinciden los individuos que conforman la multiplicidad. En el ascenso a un género superior, se renuncia a una característica determinada, a cambio de cobijar un mayor número de objetos. ${ }^{4}$ De esta manera, mientras más abstracto sea el concepto, menor será su significación para la dilucidación del individuo como tal.

La tercera observación se refiere a la subsidiariedad del concepto de relación. Es cierto que Aristóteles ha puesto particular empeño en clarificar las maneras, las gradaciones y los significados diversos del ser. También ha distinguido entre el "ser" como relación en el juicio y el "ser" como existencia de las cosas. Pero en todas estas distinciones se mantiene la primacía del concepto de substancia: las múltiples determinaciones del ser solo son pensables en substancias dadas y existentes. Las maneras lógico-gramaticales del ser refieren a un firme substrato objetivo: "Cantidad, cualidad y determinaciones espacio-temporales no existen en y para sí, sino solo como propiedades de realidades absolutas y por sí existentes" (Cassirer, 1994, p. 10).

El carácter subordinado de las categorías lógicas se ve reforzado a propósito de la categoría de relación: ella está subordinada a la esencia; la esencia es la "verdadera naturaleza", que solo puede ser afectada externamente (relación). De ahí que las relaciones "extra esenciales" puedan quedar por fuera de la definición de un concepto.

Por su parte, es preciso reconocer que Bentham no se ubica aún decididamente dentro de la lógica de la función, y de ahí que en él persista alguna dependencia de la lógica con respecto a la metafísica. En ese sentido, creo que haya de entenderse, por ejemplo, su preocupación por demostrar que el principio de utilidad no es solo una función ordenadora, sino que además viene dictado "por la constitución natural de la estructura humana", y que, en consecuencia,

4 "Si llamamos magnitud del contenido de un concepto al número de sus propiedades, esta magnitud crece cuando descendemos desde los conceptos más altos a los más bajos, y, así, disminuye el número de especies subordinado al concepto. Mientras que cuando ascendemos al género más alto, el contenido disminuirá, así como el número de especies aumentará" (Cassirer, 1994, p. 7). 
"cuando un hombre intenta combatir el principio de utilidad, lo hace, sin que sea consciente de ello, con razones extraídas del mismo principio" (Bentham, 2008a, p. 3). Solo cuando se aceptó que "no existen cosas reales que concuerden exactamente con las definiciones de la geometría" (Cassirer, 1994, p. 17) ni en el mundo externo, y ni siquiera en nuestra imaginación, solo entonces pudo desarrollarse en libertad la perspectiva constructivista, exigida desde la matemática misma, que no quiere hacer reproducciones, así sean modificadas, del mundo. A diferencia de la abstracción aristotélica, en la lógica de funciones se transforma el mundo, o para decirlo más radicalmente, se lo suplanta. Tal perspectiva no es todavía plenamente la de Bentham, y este es un factor que, como veremos, perturbará su recepción neogranadina.

Pero hecha la anterior salvedad, me parece que la concepción lógica de Bentham no se entiende si prescindimos de la lógica de la función. Así pues, junto a su afirmación del carácter "ontológico-antropológico" del principio de utilidad, Bentham quiere no obstante evitar el camino de la lógica tradicional que buscaría demostrar su validez al subsumirlo bajo algún principio superior incontestable. Situándose en una nueva perspectiva, Bentham no solo cree en la imposibilidad de dicha vía, sino que le parece que, incluso si fuera posible, resultaría inútil para sus propósitos. El valor del principio se mostrará simplemente en su capacidad ordenadora, en virtud de la cual se recomienda recurrir a su empleo generalizado:

¿Ha sido alguna vez formalmente refutada la validez de este principio? Parecería que así ha sido por aquellos que no han sabido qué han dicho. ¿Es susceptible de alguna prueba directa? Parecería que no: pues aquello que es usado para probar cualquier otra cosa, no puede ser probado él mismo [cannot itself be proved]; una cadena de pruebas debe tener su comienzo en alguna parte. Dar tal prueba es tan imposible como innecesario. (Bentham, 2008a, p. 3)

Adicionalmente, algunas insinuaciones críticas de Bentham apuntan a la insuficiencia de la teoría lógica tradicional para cumplir su cometido de conocimiento de lo real. Así, por ejemplo, en el álgido campo de la acción humana y los intereses sociales, Bentham encuentra inaplicable el procedimiento de definición del individuo mediante su adscripción al género superior de la comunidad: "es en vano hablar del interés de la comunidad sin comprender cuál es el interés del individuo" (Bentham, 2008a, p. 2). Pero, por su parte, la "lógica política" sustancialista sí cree disponer de un concepto genérico del "bien común", por lo demás bastante cercano a la "voluntad general" rousseauniana, bajo el cual debería subsumirse el interés individual. Por el contrario, el utilitarismo funcionalista de Bentham apunta a la formulación de la felicidad del mayor número a partir de una compleja (y mecánica) aritmética de sumas y restas entre los intereses individuales.

Pero si ahora quisiéramos definir en qué consiste el interés del individuo, también el procedimiento lógico tradicional exhibe idénticas limitaciones: "Interés es una de esas palabras que no teniendo ningún genus superior, no puede ser definido de la manera ordinaria" (Bentham, 2008a, p. 220).

Si la definición "ordinaria", es decir, aquella regida por el concepto de substancia, procede mediante la subsunción del objeto por definir bajo el género y diferencia específica, la alternativa propuesta por Bentham, trátese de las acciones o de los motivos que impulsan a o inhiben las mismas, consiste en atender al contexto o las circunstancias que los rodean. La consecuen- 
cia sobre su teoría moral es inmediata: ninguna acción, y tampoco "ningún motivo es constantemente [constantly] bueno o malo" (Bentham, 2008a, p. 68). La evaluación moral resulta aquí coincidente con la determinación lógica del evento individual, pero para que ellas puedan realizarse correctamente es preciso liberarse de lo que Bentham denomina "cierta perversidad de la estructura que prevalece más o menos a través de todas las lenguas" (Bentham, 2008a, p. 69). Tal "perversidad" consiste precisamente en el sustancialismo que se adhiere a las lenguas, y que opera como un caballo de Troya, en virtud del cual aceptamos sin previo examen aquello que precisamente habría de ser examinado: el valor moral del motivo. Así, por ejemplo, al examinar los motivos subyacentes a una acción, sucede "comúnmente que con el nombre mismo del motivo se implica tácitamente una proposición que le imputa una determinada cualidad; cualidad que, en muchos casos, parecerá incluir esa misma bondad o maldad, con respecto a la cual estamos aquí preguntando si, propiamente hablando, es imputable o no a los motivos" (Bentham, 2008a, p. 69).

Desde la anterior "perversión" lingüística, la lujuria o la avaricia serán siempre motivos de acción intrínsecamente malos, y caería en contradicción quien osara afirmar posibles efectos buenos de tales vicios. ${ }^{5}$ Pero la perspectiva cambia radicalmente cuando empleamos términos moralmente neutros para mencionar tales motivos - por ejemplo, deseo sexual o interés pecuniario - , abordando el asunto de su calidad moral a partir del examen de sus consecuencias tendenciales en circunstancias concretas, ${ }^{6}$ es decir, individuales.

Como puede suponerse, el examen de las circunstancias pertinentes resulta ser un cálculo muy complejo, trátese de la planeación que un individuo deba realizar en orden a conseguir sus fines, o de políticas estatales que apuntan a la utilidad del mayor número. Pero en cualquier caso, se trata de una multiplicidad de determinaciones cuyo valor no puede establecerse en términos "esenciales" sino "circunstanciales", pues este no es "sustancial" sino que se define externa o contextualmente; esa multiplicidad se ordena según un principio, el de la utilidad, que, a diferencia de lo que pensaba Bentham, no tiene que ser demostrado como "objetivo", sin que por ello pierda nada de su valor. Para decirlo en términos de Cassirer, "lo que relaciona los elementos de la serie $a, b, c,[. .$.$] no es a su turno otro nuevo elemento que estaría mezcla-$ do de hecho con ellos, sino que es la regla del progreso, que siempre permanece la misma, sin que importe en qué miembros se represente" (Cassirer, 1994, p. 21).

En su Introducción a los principios de la moral y la legislación, obra publicada cuando nuestro autor tiene 41 años de edad, el cálculo de los efectos tendenciales de la acción es considerado como relativamente acotable. Con el tiempo, llegó a ser consciente de que la complejidad de variables a ser tenidas en cuenta era mayor de lo inicialmente previsto. Entonces crecerá

5 De ahí la irritación que ya los meros títulos de los escritos de Mandeville — Una humilde defensa de los burdeles públicos o un ensayo sobre la prostitución tal como se practica actualmente en estos reinos (de 1724), o La fábula de las abejas, o los vicios privados hacen la prosperidad pública (de 1729) - suelen producir en el lector, particularmente si pertenece a una tradición cultural sustancialista, como lo es la hispanoamericana.

6 "Así pues, si cualquier clase de motivos es o bueno o malo con respecto a sus efectos, este es el caso solo en ocasiones individuales y con motivos individuales; y este es el caso tanto con un tipo de motivos como con otro. Si entonces, en consideración a sus efectos, algún tipo de motivos puede ser calificado con alguna propiedad de malo, solo puede serlo con referencia al balance de todos los efectos de ambas clases que pueda haber tenido dentro de un período dado, es decir, según su tendencia más usual" (Bentham, 2008a, p. 79; cursiva en el original). 
la importancia que Bentham otorga a una opinión pública vigorosa como instrumento del principio de utilidad: solo ella, con su discusión permanente y libre de las políticas, revelará aspectos imprevistos de las mismas, y hará más razonable su aceptación o su rechazo. Y de la mano de su creciente valoración de la opinión pública vendrá un desplazamiento político importante. En efecto, en un comienzo Bentham consideró que para la adecuada aplicación del principio de utilidad era relativamente indiferente el sistema constitucional: un déspota ilustrado bien podría llevarlo a la práctica. No obstante, una opinión pública vigorosa termina siendo incompatible con el despotismo, así sea ilustrado; entonces Bentham expresará su admiración por los sistemas republicano-constitucionales de Francia y Estados Unidos, aunque siguiera repudiando la legitimación iusnaturalista que en su momento invocaron sus respectivas revoluciones.

\section{La recepción neogranadina}

\section{a. El "sujeto" receptor}

En su escrito del 6 de septiembre de 1815, conocido como la Carta de Jamaica, Simón Bolívar describió agudamente a la élite criolla, por entonces enzarzada en una campaña militar aún incierta, pero que pocos años más tarde habría de ocuparse de las ideas del utilitarismo, con miras a encontrar algún fundamento para la nación en ciernes. Dice Bolívar:

Nosotros somos un pequeño grupo humano; poseemos un mundo aparte, cercado por dilatados mares, nuevo en casi todas las artes y ciencias aunque en cierto modo viejo en los usos de la sociedad civil. Yo considero el estado actual de la América, como cuando desplomado el Imperio Romano cada desmembración formó un sistema político, conforme a sus intereses y situación o siguiendo la ambición particular de algunos jefes, familias o corporaciones; con esta notable diferencia, que aquellos miembros dispersos volvían a restablecer sus antiguas naciones con las alteraciones que exigían las cosas o los sucesos; más nosotros, que apenas conservamos vestigios de lo que en otro tiempo fue, y que por otra parte no somos indios ni europeos, sino una especie media entre los legítimos propietarios del país y los usurpadores españoles: en suma, siendo nosotros americanos por nacimiento y nuestros derechos los de Europa, tenemos que disputar estos a los del país y mantenernos en él contra la invasión de los invasores; así nos hallamos en el caso más extraordinario y complicado. (Bolívar, 1985, p. 62)

El "nosotros" a que alude Bolívar es, sin lugar a dudas, el criollo hispanoamericano. Quizás en un solo punto su evaluación resulta errónea: aunque reconoce que el mundo del criollo es "en cierto modo viejo en los usos de la sociedad civil", es posible que su vanguardismo juvenil lo lleve a ignorar el peso de esos viejos usos, y no le permita reconocer que los jefes, familias o corporaciones en que se desintegró el Imperio romano, no son, en este aspecto, tan distintos de las fracciones hispanoamericanas resultantes de la desintegración de la monarquía 
española. También entonces, en el mundo criollo, hallaremos la tendencia a restablecer, con las correspondientes alteraciones, las "antiguas naciones". Y a la tendencia natural a la repetición de lo conocido, en el caso presente habría que sumar el hecho definitivo de que la Independencia, en su impulso original, es heterónoma: más que un movimiento anticolonial, fue el efecto más protuberante de la disolución de la monarquía española, auspiciado por la Francia napoleónica.

Por lo demás, el cuadro que pinta Bolívar es impactante: el criollo no es ni indio, ni europeo; es decir, ni es el legítimo propietario original indígena, ni el usurpador europeo (español), sino un propietario al mismo tiempo medio legítimo y medio usurpador. Aunque americano por nacimiento, no por ello podrá predicarse su igualdad con el indio, y, antes por el contrario, está en disputa con este (y con los "pardos" y con los negros). Es más bien un europeo (español), aunque por haber nacido en América, y por sufrir la invasión de los europeos (españoles), tampoco pueda decirse de él que es un europeo a cabalidad. ¡Menudo embrollo! En adelante tendrá que afirmarse - iy por supuesto que no solo militarmente!- , siempre con esa su naturaleza ambigua, frente a unos en el campo interno, y frente a otros en el campo externo. ${ }^{7}$

Pero por si lo anterior fuera poco, el proceso de la Independencia confrontó sorpresivamente al criollo con una redefinición de lo europeo. En efecto, cuando en la Carta citada Bolívar se refiere a Europa o a los europeos, el contenido semántico de estos conceptos es todavía exclusivamente peninsular: cuando dice que los derechos de los criollos son iguales a los de los europeos, es claro que se refiere a los españoles peninsulares. Pero después de la Independencia, la "Europa" con la que tiene que vérselas el criollo no será más España: pese a la Santa Alianza que intentó reconstruirla, y pese al odio que sintieron los criollos contra Napoleón, ellos tuvieron que aprender a balbucear el lenguaje político de unos interlocutores nuevos: los franceses, los ingleses, y hasta los americanos del norte. Todos ellos eran ahora "Europa"; con ella habrían de realizarse en adelante los negocios, y a ella habrían de explicar por qué pasaban los años sin que las antiguas colonias abandonasen su hispanismo y sin que en su seno se pudiesen consolidar instituciones liberal-europeas.

Al menos durante el período que aquí estudiamos, el de la primera fase de la recepción neogranadina de Bentham (1811-1836 ${ }^{\circ}$, voy a concebir al "sujeto" criollo de manera fáustica: como en el personaje de Goethe, al menos dos almas habitan en su pecho. Una de ellas vela por el mantenimiento de las relaciones coloniales internas, ahora sin la mediación de la metrópolis; la otra intenta aprender el lenguaje de la nueva Europa, sin que en su aprendizaje pueda dejar de lado improntas de su personalidad hispánico-colonial.

7 Para una caracterización más detallada, pero muy coincidente con la aquí propuesta, esta vez del criollo mexicano, véase López Cámara (1977), pp. 19-122.

8 Las dos fechas aluden, por una parte, a la primera publicación de algún fragmento de Bentham que se hace en la Nueva Granada, en el periódico La Bagatela de Antonio Nariño. La segunda fecha alude a la culminación del debate sobre el benthamismo entablado por los periódicos El Constitucional de Cundinamarca (en adelante, citado como CC, seguido del número del periódico y el año de publicación; la paginación es la de la edición citada en las referencias), pro-benthamista, y El Constitucional de Popayán (en adelante, citado como $C P$, seguido del número del periódico y el año de publicación; la paginación es la de la edición citada en las referencias), agudo crítico del benthamismo. El presente escrito se centra en este debate.

tiempo\&economía $\mathrm{N}^{\circ} 1$ - Il semestre de 2014 


\section{b. La religión católica}

Una característica protuberante de esta primera querella benthamista en la Nueva Granada es que tanto partidarios como detractores participan de una y la misma confesión religiosa: la católica. Con todo, se imponen importantes matices, que habrían de ser abordados con el detalle que ameritan en otra investigación. Por lo pronto, una diferencia fundamental parece imponerse. Mientras que la posición de conjunto exhibida por el CP es más simple, consistente y monolítica, la del CC se ve afectada por distinciones y complejidades no siempre libres de contradicción. Justamente por ello, es más interesante para los fines de este artículo.

Por lo que se refiere específicamente a la cuestión religiosa, frente a la previsible presencia omnicomprensiva del catolicismo en el $C P$, la tipología, por desgracia apenas esbozada por Bernice Hamilton, puede iluminar la compleja posición exhibida desde las columnas del CC. ${ }^{9}$ Así pues, en lo que se refiere a la importancia de la "verdadera religión" para la vida humana, ambos bandos coincidirán en que esta es la religión católica. Pero los matices de la aceptación son diversos. En efecto, mientras que en el CP se profesa la fe católica, considerándola como fundamento incuestionable de la vida individual y pública, el CC quiere más bien considerarla como un dato cierto de la vida privada, pero del que no pueden derivarse los principios fundamentales de la legislación. De esta manera, aunque el articulista del CC no tiene problema en convenir "ante todas las cosas, en que, entre la multitud de religiones que existen y han existido, solo la de Jesucristo es la verdadera" (López, 1993, p. 218), al mismo tiempo juzga como evidentemente absurdo que los legisladores de pueblos no cristianos hubiesen de adoptar a esta religión revelada como base de sus razonamientos jurídicos. ${ }^{10}$

Por lo que se refiere a la funcionalidad cívica de la religión, es decir, a la posibilidad de asociación de virtudes religiosas y cívicas, el CC cree poder llegar a una fácil solución de compromiso. Frente al incuestionable fundamento católico de la moral social, el utilitarista criollo cree poder evitar el conflicto, citando al propio Bentham, que recomienda el uso del móvil religioso, siempre y cuando se le dé la "dirección conveniente" (López, 1993, p. 217). Sin embargo, pese a algunas, e incluso a muchas, coincidencias que puedan existir entre la moral utilitarista y las doctrinas evangélicas y eclesiásticas, existen diferencias insalvables que quitan plausibilidad a la fusión propuesta por el CC. El telos católico está situado en el más allá, y su promesa de felicidad o condenación en esa otra vida resulta irrazonable — cuando no perversa - para el utilitarista, que busca el bienestar colectivo en esta.

Finalmente, apenas si encontramos en la polémica entre los dos periódicos alguna referencia directa a lo que atañe al papel de la religión en la consolidación de la unidad nacional. Pero por fuera de estos artículos, podría ser que los partidarios del benthamismo hayan reclamado privilegios derivados de una tradición de patronato estatal que se remonta hasta los Austria, y que después de la Independencia les resultarían aprovechables para una concepción más

9 En su exposición sobre el pensamiento político de una serie de destacados teólogos españoles del siglo XVI, dice Hamilton: "Si analizamos estos argumentos, podemos encontrar tres temas diferentes: la importancia vital de la 'religión verdadera' para todos los hombres, la asociación entre virtudes religiosas y cívicas [...], y la asunción contemporánea de que la unidad de un país exigía unanimidad religiosa" (Hamilton, 1963, p. 114).

10 "[...] es necesario que recordemos: que las naciones que pueblan la tierra tienen distintas creencias religiosas, distintos gobiernos, distintas costumbres; que sería obra no solo difícil sino imposible el hacerles cambiar cuando se quiera de religión, de gobierno, de costumbres" (López, 1993, p. 215). 
"republicana" del significado de una religión como factor de unificación de una nación. ${ }^{11}$ Por su parte, los detractores del benthamismo quisieron ser un apoyo para políticas vaticanas que, disuelta la monarquía, aspiraron a apuntalar una absoluta superioridad del magisterio apostólico-doctrinal de una iglesia católica - es decir, universal- pero además romana. Arengas pueblerinas y que apelan al fondo supersticioso de los neogranadinos como las mantenidas por los presbíteros Francisco Margallo (cfr. López, 1993, pp. 26-52) o José María Botero (cfr. López, 1993, pp. 184 y ss., y Moreno de Ángel, 1990, pp. 650-655) pueden ganar un cierto interés bajo esta luz. ${ }^{12}$

\section{c. El derecho natural}

Ya hemos visto que uno de los mayores esfuerzos hermenéuticos de los utilitaristas criollos fue mostrar que los principios centrales de su teoría no contradecían los presupuestos católicos. ${ }^{13}$ Por su parte, los detractores no ahorraron esfuerzos para mostrar la incompatibilidad, $y$, por ende, la necesidad de renunciar al catolicismo si se querían adoptar los postulados benthamistas. La empresa de los segundos pudo ser más coherente y perspicaz para percibir las consecuencias de los principios utilitaristas, inaceptables para ellos, si bien su comprensión de dichos principios dista de ser satisfactoria.

11 Santander sería un caso paradigmático para ilustrar lo dicho acerca de las diversas funciones de la religión, y de sus relaciones con el Estado. Así, en su polémica con el ultramontano presbítero Botero, no tiene inconveniente en afirmar: "Yo, mi respetado doctor, nunca he hecho profesión de incrédulo. Amo mi religión, porque felizmente la conozco, y sé que fuera de la Iglesia católica no hay salud eterna" (Moreno de Ángel, 1990, p. 651). El óleo de Luis García Hevia que representa la muerte de Santander —quizás mucho más que la versión del mismo evento por José María Espinosa, ambos en el Museo Nacional de Colombia-confirma la anterior declaración, al mostrar a un compungido arzobispo Mosquera en afectuosa cercanía a Santander recién fallecido. Pero junto a la función de la religión en lo que se refiere a la "salud eterna", no es de menor peso el complejo equilibrio que implica la religión republicanamente entendida. Así, Santander le reconoce al auditor de la Internunciatura vaticana, monseñor Lorenzo Valenzi, la dependencia de la Nueva Granada de la Silla apostólica, si bien insinuando que ello es así por mor del marco republicano: “La Nueva Granada es católica y también republicana, y constantemente reconoceremos en la silla apostólica la dependencia que por nuestra creencia religiosa debemos tener" (Moreno de Ángel, 1990, p. 662). Sin embargo, no sin amargura el Internuncio monseñor Baluffi se quejaba de que en la ceremonia de presentación de credenciales, "no se recató el General Santander de anunciar públicamente que las leyes granadinas deberán servir de normas al Internuncio Apostólico en el ejercicio de su misión" (Moreno de Ángel, 1990, p. 658).

12 La acusación referente al énfasis supuestamente hedonista en las ideas benthamistas de placer y dolor bien puede explicarse como táctica demagógica de púlpito, frente a un público no muy ilustrado y en cambio sí más bien analfabeta. Mirado con exactitud, el utilitarismo es, por el contrario, un dispositivo de control, sin el que el hedonismo causaría estragos antisociales de consideración. El presbítero Botero enardecía a sus fieles con acusaciones tales como que Bentham afirmaba que Jesucristo era un pícaro, y que predicaba la lascivia y todo tipo de aberraciones hedonistas. Santander lo zahiere cáusticamente: "Es menester desengañarse, mi querido doctor; un predicador de aldea no puede predicar ya en las ciudades, es menester que se provea de ciencia y piedad, para que no sea burlado" (Moreno de Ángel, 1990, p. 652). Con todo, no resulta claro qué tan cosmopolitas podían ser nuestras urbes.

13 Pensando en ellos, bien podría haber dicho Bentham: "Hombres de las peores religiones, influenciados por la voz y la práctica del mundo circundante, se apropian continuamente de una y otra página del libro de la utilidad; y con ellas, con miras a no romper con la religión, intentan, a veces con bastante violencia, remendar y adornar los repositorios de su fe" (Bentham, 2008a, p. 85). 
Así, por ejemplo, el redactor pro benthamista de un extenso artículo publicado en 1836 no vacila en partir de una antropología sustancialista, constituida teleológicamente, en la que la búsqueda del placer y la tendencia a evitar el dolor son mecanismos pensados por Dios para que con su ayuda el hombre alcance las metas para las que fue creado. ${ }^{14}$ Afirma además la identidad de contenidos entre los postulados utilitaristas y los mandatos derivados del derecho natural. Desde su punto de vista, no solo el derecho natural ofrece un catálogo de acciones buenas o virtuosas y otro de malas o viciosas —algo así como en un vademécum-, sino que además el utilitarismo terminaría por expresar su doctrina en la misma forma, y por supuesto que en todo coincidente con el derecho natural. En concesión a las "buenas costumbres" de una sociedad que suponemos muy tradicional, nuestro articulista utilitarista concluye que "un hombre de buena fe que quisiese obrar bien, dirigiendo su conducta por el utilitarismo, no se entregaría al hábito de la embriaguez" (CC, 225, 1836, p. 193). ${ }^{15}$

En su defensa del utilitarismo, el CC quiere minimizar el frontal ataque de Bentham al derecho natural, convirtiéndolo en un asunto de meras diferencias de método cognoscitivo. ${ }^{16} \mathrm{El}$ utilitarismo criollo - ipero no Bentham! - no quiere entonces negar el derecho natural, sino impugnar la manera como supuestamente acceden a él los enemigos payaneses de Bentham; al innatismo, la ciencia infusa o la recta razón, ellos oponen la investigación empírica. ${ }^{17}$

Por lo demás, los utilitaristas criollos parecen olvidar que desde el punto de vista de su defendido habría que evitar esa "perversa" tendencia del lenguaje que nos lleva a presuponer la existencia de acciones intrínsecamente virtuosas o viciosas. Y también olvidan que sería menester proceder a una denominación neutral de las mismas, y que solo entonces podrá

14 "Pero nosotros los humanos que creemos, que habiéndonos dado el creador la mayor porción de su bondad, organizándonos de manera que necesariamente estemos sintiendo agradable o desagradablemente, o habiéndonos impuesto la tendencia a procurarnos lo primero y a evitarnos lo segundo; habiendo hecho esto, repetimos que tenemos el conocimiento de que estas inclinaciones son inocentes, y que no se dirá ser un crimen a los ojos de la divinidad el ceder a este impulso; y de aquí concluimos que nos [aunque la edición citada dice "no", creo que se trata de un error de transcripción, y que debe decir "nos" LP.] son permitidos los medios indispensables para lograr este fin" (CC, 225, 1836, p. 187).

15 "Las únicas diferencias que se hallan entre los dos partidos están en el modo de buscar, conocer y explicar esa buena moral y esa buena legislación, y aún en cuanto a esto ellos se aproximan a medida que se explican" (CC, 225, 1836, p. 196). No obstante, tal como lo afirmará el adversario desde el periódico de Popayán (CP, 160, 1835 , pp. 170 y ss.), resultaba imposible que desde el catolicismo llegara a afirmarse, como sí lo hace Bentham, que el aborto - y también el "infanticidio" - es asunto privativo de los padres. Tampoco hubiese estado de acuerdo con Bentham - sus escritos al respecto han sido recientemente publicados- en que la homosexualidad es de incumbencia exclusiva de los implicados (cfr. Bentham, 2008b), o en que el divorcio no es el efecto de épocas sociales putrefactas.

16 "La cuestión se reduce a lo siguiente: ¿el hombre trae consigo, al nacer, grabado el conocimiento de las acciones buenas y malas? O mejor dicho: ¿es infusa en los hombres la ciencia de lo bueno y lo malo? O más claro, ¿hay en el hombre ideas innatas? No, dice Bentham; y eso es lo que niega al decir que no hay ley natural" (CC, 226, 1836, pp. 201 y ss.).

17 "Importante es sobremanera conocer todas estas leyes, este enlace entre los fenómenos ya físicos, ya morales. ¿Pero de esto es preciso concluir que las leyes del orden físico son las que promulgó Dios por medio de la recta razón? ¿Será necesario decir que la eterna razón grabó en todos los corazones el conocimiento de la física? Las leyes a que la divinidad sometió todos los seres, no las ha promulgado de diferente modo; y las que rigen el mundo moral no las grabó más en nuestros corazones que grabó en ellos el conocimiento de la cirugía y la medicina" (CC, 226, 1836, p. 203). 
practicarse la "aritmética contextual", de la que surgirá la valoración moral de los casos individuales. Solo desde un horizonte substancialista resulta plausible la pretensión de clasificación, a priori, de los actos como intrínsecamente perversos o virtuosos. Solo desde una lógica de la función resulta posible la definición del "valor" de una acción a partir de la determinación de sus relaciones externas.

Aunque sin comprender tampoco cabalmente los fundamentos lógicos del adversario, la hermenéutica del contradictor del utilitarismo que se despliega en el Constitucional de Popayán resulta en cambio más libre, menos presa del compromiso de buscar a toda costa la compatibilidad entre doctrinas que, al menos en principio, parecen mostrarse como inconmensurables. Así, para el $C P$, los principios que rigen las obras de Bentham "no son conformes a la moral natural, ni a la religión católica, ni a los principios políticos de la Nueva Granada" (CP, 160, 1835, p. 162; cursivas mías); ellos son "contrarios a la moral universal y destructores de la moral cristiana [...] niega(n) la revelación, y sustituye(n) como bases de su moral el placer y el dolor, diciendo que entiende $(n)$ por placer y dolor lo que se entiende vulgarmente" $(C P, 160,1835, p$. 165). Y no le falta razón si pensamos en una religión, la de los neogranadinos, fundada en conceptos substancialistas, para la que, en consecuencia, pueden existir acciones con valor moral intrínseco, además de un derecho natural al que han de conformarse tanto la acción individual como la ordenación política humana. Nada más extraño a ello que la evaluación de las acciones desde el punto de vista de una utilidad desvinculada de toda consideración acerca de los fines esenciales de la naturaleza humana, y en la que ni siquiera el establecimiento de tendencias exime del examen renovado frente a coyunturas específicas cambiantes. Y, por supuesto, nada más difícil que la evaluación de la individualidad de una acción, cuando solo se dispone de una lógica que de antemano declara la inefabilidad del individuo.

\section{d. La ciencia política criolla}

Una interpretación adecuada del utilitarismo - la cual no implica necesariamente una adhesión al mismo - no puede ser realizada en clave aristotélica, es decir, en términos de una lógica de la substancia. Por su parte, el mundo criollo - tanto de defensores como de detractores de Bentham - no parece haberse desplazado al concepto de función. En esas condiciones, nada más comprensible que la afirmación hecha desde las páginas del Constitucional de Popayán, según la cual Bentham "tiene la extravagancia de invertir el orden de la naturaleza" (CP 161, 1835, p. 175; cursivas mías).

El antibenthamista de Popayán no rechaza ni la necesidad, ni la legitimidad de la búsqueda de la felicidad. La "extravagancia" que encuentra en el utilitarista, su "inversión del orden de la naturaleza", consiste en concebir la felicidad o la utilidad como causa, y no como lo que es, es decir, efecto. Pero lo que está en juego dista mucho de ser una mera obsesión por el orden lógico: al asegurar la prioridad para la causa, la ciencia política escolástica garantiza la presencia rectora de los postulados del derecho natural, con su noción de justicia. ${ }^{18}$

18 "Nosotros pensamos que la localidad de los principios fundamentales es al principio de toda ciencia, y no deben colocarse en parte de ella; [...] la utilidad es una verdad de consecuencia, y debe tener una localidad subalterna; y que no se debe aspirar a socavar las nociones primeras de lo justo y los deberes y derechos que 
Así, del obrar justo se derivará la consecuencia que es la felicidad del hombre o de los pueblos. $^{19}$

Una consecuencia inmediata del anterior planteamiento, y de vital importancia en los momentos de fundación del orden político que ha de seguir a la Independencia, es la estabilidad social ofrecida por esta teoría. Por ello, el de Popayán afirma que la construcción de un orden social sólido posindependentista debe acudir más a fundamentos ideológicos tradicionales de probada eficacia, que a innovaciones con resultados harto inciertos. Y entonces, haciendo gala de una noción bastante limitada del cálculo - que en nuestra historia intelectual siempre se utilizó para desprestigiar al utilitarismo—- el CP estima que el cálculo en virtud del cual alguien tendría que concluir que no ha de robar, se limita a equiparar la ganancia del ladrón con la pérdida de la víctima. Pero entonces resultará obvio que para el ladrón pesará más su ganancia. En estas condiciones, la eventual fuerza constrictiva del cálculo — utilitarismo — resultaría irrisoria frente a la que tendría el simple pero taxativo y absoluto deber de no robar, derivado de la justicia propia del derecho natural.

Pero aunque no tengan una cabal comprensión de la lógica que anima los principios del utilitarismo, sus opositores criollos saben bien que ellos no son conformes ni "a la moral natural, ni a la religión católica, ni a los principios políticos de la Nueva Granada" (CP 160, 1835, p. 162; resaltado mío). Esta declaración contradice la evaluación del Bolívar de la Carta de Jamaica: para el de Popayán, la Nueva Granada, tal como reconocía Bolívar para los fragmentos en que se disolvió el Imperio romano, también tiene principios políticos propios, y a ellos -y no a los de un improvisado embeleco utilitarista - se ha de recurrir para la fundación de la nación.

Resulta comprensible que para la perspectiva social colonial abruptamente enfrentada con la realidad de la Independencia, el utilitarismo represente un salto al vacío, en el que la pérdida de sentido de nociones como alma inmaterial o derechos naturales inalienables e imprescriptibles se traduzca en un oscurecimiento de las verdades morales. Y también se entiende que le resulte insoportable lo que en una sociedad individualista es condición de supervivencia, porque la realización de los intereses no está asegurada corporativamente: el cálculo que se ajusta a las condiciones siempre cambiantes. Para el antiutilitarismo criollo, el cálculo no solo representa una "condena al escepticismo" sino "a formar la evaluación forzada de los intereses y acciones de cada día, para ver si eran útiles, o lo que es lo mismo, placenteras o penosas físicamente" (CP 168, 1836, p. 235)

Para una mentalidad corporativa, tampoco puede resultar asimilable la concepción utilitarista de la ley, que solo exhibe su plena necesidad en una "sociedad de individuos". El legislador utilitarista tiene la compleja tarea de promover o impedir acciones con miras a obtener la mayor felicidad posible del mayor número posible. La“ley" es entonces el resultado — por cier-

son la base fundamental de la moral. Estas bases son útiles porque son invariables, y no son invariables o rectas por ser útiles" (CP 168, 1836, p. 248; véanse también CP 160, 1835, p. 172, y CP 168, 1836, p. 230).

19 El autor de Popayán cita a Benjamin Constant: “Querer someter el derecho a la utilidad es querer someter las reglas eternas de la aritmética a nuestros intereses de cada día. Es útil, sin duda, para las transacciones generales entre los hombres, que existan relaciones inmutables entre los números; pero si se pretendiese que estas relaciones existen solamente porque es útil que así sea, no faltarían ocasiones para probar que sería infinitamente más útil hacer ceder estas relaciones; se olvidaría que su utilidad constante viene de su inmutabilidad, y dejando de ser inmutables dejarían de ser útiles" (CP 160, 1835, p. 168). 
to que siempre provisional- de una compleja aritmética que acoge el mayor número posible de variables, y mientras no sea transformada mediante procedimientos previamente establecidos, sirve de pauta inamovible. ${ }^{20}$ Pero el "consenso" que la ley expresa no representa ninguna esencia comunitaria prepolítica, ni ninguna "voluntad general", y siempre implicará el sacrificio de intereses de individuos o grupos si estos llegan a estar en contravía de lo que se estima como interés mayoritario. Esta concepción de la ley como expresión del interés de la mayoría nace de la temprana oposición de Bentham al derecho consuetudinario, expresado en este caso en sus Comentarios a las leyes de Inglaterra de Blackstone. La common law, no siempre escrita, con su carácter ambiguo, antitécnico, contradictorio con respecto a otras leyes, era en realidad el instrumento de defensa de los intereses de minorías aristocráticas muy precisas.

Desde su perspectiva lógica, nuestro antiutilitarismo criollo solo podía juzgar como aberración el carácter indudablemente "sofístico" de la concepción utilitarista de la ley. Para él, la justicia pertenece al orden natural, y la ley positiva será justa, y solo entonces causa de felicidad, si traduce adecuadamente ese orden natural. ${ }^{21}$ Pero lo que la ley expresa cuando es justa no puede ser ese simple interés aritmético, desarraigado y arbitrario que es el interés de la mayoría. En clave que también podría ser rousseauniana, el CP está pronto a afirmar que la ley justa puede ser de "utilidad general", incluso contraviniendo el interés de la mayoría. Y por lo demás, las nivelaciones que imponga la ley concebida a la manera de Bentham no serán más que meros "sacrificios" heterónomos, carentes del valor que tienen las transacciones, tal como las concibe una concepción corporativa de sociedad. ${ }^{22}$

Así pues, en contra de lo estimado por Bolívar en 1815, el alma antibenthamista que anida en el fáustico y dual pecho criollo de 1835 es consciente de que el orden social que desea, y salvo por la eliminación forzada de la mediación peninsular, no difiere fundamentalmente del orden social colonial, y solo resulta alcanzable mediante la continuación de los principios de la politología escolástica. Los fundamentos de la aritmética utilitarista le resultan contra natura, y por ello, fundamentalmente débiles; los resultados que promete son inciertos.

20 "El mayor bienestar del número más grande exige que se admita el número más grande de posibles competidores, tanto para trazar el código en cuestión como para proponer las enmiendas, una vez que el código haya sido aceptado" (Bentham, 1823, p. 10).

21 "El filósofo moralista y legislador, que consulta las leyes naturales del orden físico y los axiomas evidentes a su razón, saca consecuencias conformes a las leyes naturales, que por ser rectas se llaman justas. Entonces el hombre se pone en armonía con las leyes naturales y en esto consiste su felicidad; y como todo lo que hace su felicidad se llama útil, se encuentra que todo lo que es justo es útil" (CP 168, 1826, p. 230).

22 "Los partidarios del principio de la justicia no admitimos gobierno en principio de la mayoría, porque nuestro fin último es la utilidad general; y no el provecho del agente, aun cuando sea el agente una fracción mayor de la sociedad. Nosotros sostenemos que en una sociedad bien organizada hay transacciones y no sacrificios de unos a favor de otros" (López, 1993, p. 227). 


\section{Conclusión}

Pero ¿qué decir ahora de la concepción política de esa otra alma que habita el fáustico pecho neogranadino? ¿Del alma criolla proclive al utilitarismo?

En un interesante estudio, relativamente reciente (2006), el historiador Armando Martínez Garnica ha ofrecido un inventario de reivindicaciones por él llamado La agenda liberal temprana en la Nueva Granada (1800-1850). A diferencia de lo que pensaron notables publicistas liberales neogranadinos agrupados en la llamada Generación del 7 de marzo de 1848, Martínez Garnica afirma que buena parte del programa político propuesto por este grupo no es producto original suyo, sino que vino abriéndose camino desde el comienzo mismo del movimiento independentista, a inicios del siglo.

Es claro que la única fuente ideológica de estas diversas reivindicaciones no fue el utilitarismo de Bentham. Al lado de este, y en ocasiones más importantes, han debido ser las ideas provenientes de las revoluciones Francesa y Norteamericana, o el pensamiento de Rousseau. $Y$, por supuesto, las doctrinas pactistas que tienen su fuente en la neoescolástica española, particularmente en su versión suareciana.

En este contexto, resulta muy sugestiva la reseña hecha por Martínez (2006, pp. 29-51) acerca de la distinta suerte obtenida por las tres versiones de la Declaración de los derechos del hombre y del ciudadano en su recepción neogranadina. Así, por ejemplo, no deja de ser significativo que la primera versión, la de 1789, aquella que podría considerarse como la más representativa del espíritu liberal burgués y que además fuera objeto de la famosa traducción del Precursor Antonio Nariño, prácticamente careció de efectos en el ideario político y constitucional neogranadino. En cambio, cosa muy distinta sucedió tanto con la versión más popular-jacobina de 1793, cuyas eventuales afinidades electivas con la tradición pactista estarían por estudiar, como también con su antagonista, la de Fructidor de 1795, cuya declaración, en el sentido de que "nadie puede ser buen ciudadano si no es buen hijo, buen padre, buen hermano, buen amigo, buen esposo", tanto emocionara a tirios y troyanos del criollismo. Una y otra versión, con todas sus diferencias, pueden ostentar, no digo que igualdades, aunque sí afinidades con la tradición pactista, que las hacen más simpáticas al liberal neogranadino.

Existen más iniciativas — no todas, a mi juicio, necesariamente "liberales", como el "amor a la patria" (chica)—, algunas de las cuales exhiben, incluso hoy en día, una suerte incierta: así, por ejemplo, las Sociedades económicas de amigos del país, de clara herencia hispánica, que propiciaban un desarrollo de las artes y los oficios en una sociedad sobresaturada de curas y abogados. En nuestros días podríamos llamarlas institutos tecnológicos, y contrapuestas a las universidades, siguen mereciendo escaso reconocimiento social.

Martínez reseña la activa participación de uno de los supuestos autores del CC en la defensa de la libertad de imprenta, el publicista liberal Vicente Azuero, claramente comprometido con la defensa y difusión del ideario utilitarista. Como Bentham, Azuero piensa que es una opinión pública fuerte -y no el Imprimatur, ni el Nihil obstat - la que debe frenar los posibles abusos de esta libertad. También Azuero desempeñará destacado papel como cultor del espíritu constitucionalista, e incluso se enfrentará a las veleidades dictatoriales de Bolívar. 
Una amplia gama de políticas adicionales configuran pues esta "agenda liberal temprana", no plenamente realizada ni para la época de la Generación del 7 de marzo de 1848, pero tampoco incluso en nuestros días: la abolición de la esclavitud, decretada en la Constitución de Cúcuta de 1821 pero solo realizada cabalmente en 1852; la desamortización de los resguardos y el libre mercado de las tierras, la modernización y simplificación de las políticas fiscales, la construcción de una red de vías de comunicación, una real división del poder supremo, la abolición de los fueros o la construcción de políticas educativas públicas sólidas. Para toda esta "agenda", bien cabe decir aun en nuestros días: "sin duda, era un proyecto de cuño liberal, como repitieron con alguna frecuencia. Pero estos publicistas tenían que enfrentar el aplastante peso de las tradiciones políticas y de los prejuicios sociales del antiguo régimen" (Martínez, 2006, p. 170).

Las dificultades experimentadas por estos publicistas liberales de la primera generación se siguieron repitiendo, según lo afirma uno de sus colegas de segunda generación, José María Samper, cuando intentaba ilustrar, en 1861, a un público europeo que no acababa de entender la inestabilidad institucional colombiana, cuarenta años después de su independencia. Para Samper, se trataba de una guerra "entre la Colonia, que resiste y quiere vivir, como la hiedra en los escombros, y la democracia, que avanza, cobra bríos y espera sin cesar. Las luchas no acabarán sino el día en que la Colonia haya sido arrancada de raíz y pulverizada, desapareciendo el dualismo de tendencias enemigas" (citado por Martínez, 2006, p. 7).

Cien años más tarde de la anterior declaración -y ciento cincuenta después de la Independencia- el politólogo norteamericano Glen Dealy observó que aún permanecían los mismos "desajustes" entre Colonia y democracia; entonces concluyó la radical inadecuación del planteamiento que explicaba la historia de Hispanoamérica, al menos hasta el decenio de los sesenta del siglo pasado, como una oscilación entre el gobierno "real", arraigado en la tradición colonial (elecciones amañadas, caudillismo, represión generalizada de los derechos individuales), y la superestructura gubernamental "no real" basada en constituciones e ideologías prestadas. Según esta concepción, la tarea consistiría en superar ese abismo cuya profundidad explicaría y excusaría el no haber establecido una democracia que funcionara realmente, pese a que supuestamente ella constituía el ideal incuestionable de los líderes independentistas (cfr. Dealy, 1968, pp. 40 ss.).

Según Dealy, la realidad del proceso histórico-político hispanoamericano había sido mal diagnosticada. No existían dos tradiciones - por una parte, la hispano-católica-colonial y "práctica", y por otra, la democrática y liberal, en teoría-, sino que:

Existe una única tradición hispanoamericana, y esa tradición exhibe más bien una unidad cerrada entre teoría y práctica. [...] Los hispanoamericanos en 1810 no rompieron con los ideales y prácticas de su pasado colonial, ni rechazaron trescientos años de instituciones hispano coloniales [... $]^{23}$ Panfletos políticos de la era de la

23 En la misma perspectiva, con especial referencia a México y Brasil, véase el trabajo más reciente de Ulrich Mücke Gegen Aufklärung und Revolution. Die Entstehung konservativen Denkens in der iberischen Welt (17701840). 
independencia muestran que sus autores poseían un genio notable para adoptar el lenguaje, estilo y entusiasmo de la época, mientras que mantenían su propia herencia no democrática casi intacta. (Dealy, 1968, pp. 41 y 42)

El anterior planteamiento difiere pues radicalmente tanto del de los publicistas liberales de mediados del siglo XIX que atribuían los males de la república a la persistencia de "la Colonia" como del de historiadores contemporáneos como Martínez Garnica que afirman que desde sus comienzos la sociedad hispanoamericana postindependentista habría estado empeñada en la realización de los ideales democrático-liberales. Desarrollando el punto de vista de Dealy, quizás podría afirmarse que el discurso liberal temprano criollo fue más bien un lenguaje impuesto por una constelación internacional (Francia, Inglaterra, Estados Unidos) que ahora difería rotundamente de lo que hasta entonces fue el exclusivo referente de la metrópolis peninsular: "Europa” ya no era lo que Bolívar pensaba de ella en 1815. Pero así como la independencia fue un hecho sobreviniente, la construcción de un nuevo orden político sin la mediación española no parecía requerir, a los ojos criollos, elementos nuevos o distintos a los ya conocidos por "las tradiciones políticas de la Nueva Granada".

Así pues, pese a las proclamas constitucionalistas suscritas por los publicistas liberales y más bien destinadas para el público europeo, lo que en realidad habría persistido es un escepticismo interno frente a las reglas, los procedimientos e instituciones del gobierno constitucional como los mecanismos idóneos para mantener bajo control los desbordamientos del interés personal. Se siguió de allí que se considerara que el buen gobierno dependía más del reclutamiento de hombres buenos - el gobernante ha de ser "de reconocida virtud, talento, patriotismo probado en la comunidad"- que de instituciones vigorosas (cfr. Dealy, 1968, p. 44).

El "eclecticismo" criollo resultaría ser entonces algo mucho más complejo que una simple exhibición de pragmatismo más o menos apresurado. El derecho natural moderno, presente en las declaraciones norteamericana y francesa, tiende a ser el mascarón de proa de una tradición propia, distinta y colonial, de ley natural. A la obligación consagrada en todas las primeras constituciones de asumir, propagar y defender los principios católico-romanos, con la visión jerárquica de la sociedad que ellos conllevan, se superpone, sin solución de continuidad, la proclamación de los derechos del hombre y del ciudadano.

Así mismo, se asume la doctrina moderna que funda el control del poder en su separación en las ramas ejecutiva, legislativa y judicial, o en la distinción de competencias entre gobierno central y local. Pero ya durante la fase primera posterior a la independencia, Dealy descubre (1968, p. 46), tras la aceptación formal de la división de poderes, una tendencia aristocrática en la que el poder legislativo se imponía sobre los otros dos. Pronto esta será reemplazada por la tendencia dictatorial, o al menos de franca primacía de un poder ejecutivo que puede disponer a voluntad del estado de excepción, sin que se consolide cabalmente el sistema de "pesos y contrapesos".

El presupuesto central de la doctrina liberal y también del utilitarismo es la diversidad irreductible de intereses sociales. Por ello, la única forma de garantizar la convivencia social reside en su negociación y aritmética, cuyo resultado es la ley. Esta expresa acuerdos provisionales, que no deben ser confundidos con una noción positiva de "bien común", ni de "voluntad general". Pero esta nunca fue la meta del ideario político neogranadino, el cual, por 
el contrario, siempre insistió en la búsqueda de la unanimidad como virtud, acaso influido por la experiencia de una unanimidad religiosa que nunca estuvo realmente amenazada. La conclusión de Dealy es inquietantemente rotunda: "es posible que el 'fracaso' de los gobiernos hispanoamericanos tanto en 1810 como en 1966 no sea en realidad un fracaso en alcanzar la democracia, sino un triunfo de los ideales y aspiraciones que fueron suyos desde la Colonia" (Dealy, 1968, p. 52).

Desde el punto de vista de Dealy, no habría pues un tal "pecho fáustico criollo", dividido entre un alma antiutilitarista, católica y colonial, y otra liberal, democrática y utilitarista. Tal vez el calificativo adecuado sería más bien el de un "pecho hipócrita", que engatusa al exterior con una apariencia de modernidad, mientras que prolonga en el interior un modelo de dominación exitoso por más de tres centurias. Ahora bien, el reconocimiento de la persistencia del legado colonial, no ya en 1966, sino incluso en 2014 - y ese es el servicio que nos prestan análisis como el de Dealy-, no tiene sin embargo que llevarnos a la conclusión del mismo Dealy, ${ }^{24}$ que, afectado por los temores de la Guerra Fría, consagraba como distintivo de Latinoamérica - pero lógicamente que también del mundo hispánico en su conjunto- un "monismo" que repugna al pluralismo, al parecer patrimonio exclusivo de la tradición anglosajona. De la cortesía (politesse), y en general de la galantería cortesana, decía Kant algo que bien podríamos aplicar a la "hipocresía" de nuestras formas liberales criollas: "no engañan porque cualquiera sabe cómo debe tomarlas, y principalmente porque estos signos de benevolencia y respeto, inicialmente vacíos, conducen poco a poco hacia caracteres reales de este tipo" (Kant, B/A 45).

\section{Referencias}

Bentham, J. (1823). Essais sur la situation politique de l'Espagne, sur la Constitution et sur le nouveau Code Espagnol, sur la Constitution du Portugal, etc., etc. París: Librairie de Brissot-Thivars,

Bentham, J. (2008a [1789]). An Introducción to the Principles of Morals and Legislation. Nueva York: Barnes and Noble.

Bentham, J. (2008b). Contra la homofobia. México: Tumbona Ediciones S.C. de R.L. de C.V.

Bolívar, S. (1985). Carta de Jamaica. En Doctrina del Libertador. Caracas: Biblioteca Ayacucho.

Borah, W. (1963). Colonial Institutions and Contemporary Latin America. Durham, N. C.: The Duke University Press.

24 "El peligro que acecha a nuestra política exterior y a las ciencias sociales es que no reconozcamos esta diferencia fundamental entre las aspiraciones políticas de Latinoamérica y de Norteamérica. No reconociendo esta diferencia podríamos involuntariamente obligar a Latinoamérica a escoger entre un pluralismo norteamericano o un marxismo monista. Provocando esta elección, debemos estar conscientes de que el marxismo tiene coincidencias monistas por el pasado latinoamericano que nuestro sistema no puede igualar. Brenan ha esbozado tanto estas coincidencias como las existentes entre jesuitas y marxistas. Felizmente esa no es la única disyuntiva. La verdadera alternativa para Latinoamérica está entre las diversas formas del monismo político. Como nación nosotros tenemos los medios para influir en esa decisión: podemos 'cargar la tinta' hasta hacer empalagoso el pluralismo, o podemos aceptar y apoyar un gobierno de tipo monista aceptable para su pasado y para nuestros intereses" (Dealy, 1974-75, pp. 183 y ss., Nota 4). 
Cassirer, E. (1994). Substanzbegriff und Funktionsbegriff. Untersuchungen über die Grundfragen der Erkenntniskritik. Darmstadt: Wiss. Buchges.

Constitucional de Cundinamarca (CC). López, L. H. (comp.). (1993). La querella benthamista 17481832. Bogotá: Biblioteca de la Presidencia de la República.

Constitucional de Popayán (CP). López, L. H. (comp.). (1993). La querella benthamista 1748-1832. Bogotá: Biblioteca de la Presidencia de la República.

Dealy, G. (1968). Prolegomena on the Spanish American Political Tradition. Durham, N. C.: The Duke University Press.

Dealy, G. (1974-75). La tradición de la democracia monista en América Latina. Universidad de PittsburghPittsburgh

Gilmore, R. L. (1995). El federalismo en Colombia 1810-1858. Bogotá: Sociedad Santanderista de Colombia - Universidad Externado de Colombia.

Gross, R. (1999). "Jewish Law and Christian Grace". Carl Schmitt's Critique of Hans Kelsen. En D. Diner y M. Stolleis (eds.), Hans Kelsen and Carl Schmitt. A Juxtaposition. Gerlingen y Tel Aviv: Bleicher Verlag.

Hamilton, B. (1963). Political Thought in Sixteenth-Century Spain. A Study of the Political Ideas of Vitoria, De Soto, Suárez and Molina. Oxford: Clarendon Press

Hobbes, T. (1994 [1668]). Leviathan. Indianapolis/Cambridge: Hackett Publishing Company.

Kant, I. Anthropologie in pragmatischer Hinsicht, Weischedel W. (ed). Fráncfort : Suhrkamp Verlag

López Cámara, F. (1977). La génesis de la conciencia liberal en México. México: UNAM.

López, L. H. (comp.). (1993). La querella benthamista 1748-1832. Bogotá: Biblioteca de la Presidencia de la República.

Marquínez Argote, G. (1983). Benthamismo y antibenthamismo en Colombia. Bogotá: Editorial El Búho.

Martínez Garnica, A. (2006). La agenda liberal temprana en la Nueva Granada (1800-1850). Bucaramanga: Universidad Industrial de Santander.

Moreno de Ángel, P. (1990). Santander. Biografía. Bogotá: Planeta.

Morse, R. M. (1982). El espejo de Próspero. Un estudio de la dialéctica del nuevo mundo. México: Siglo XXI Editores.

Mücke, U. (2008). Gegen Aufklärung und Revolution. Die Entstehung konservativen Denkens in der iberischen Welt (1770-1840). Colonia,Weimar y Viena: Böhlau Verlag.

Posada Carbó, E. (2011) La tradición liberal colombiana del siglo XIX: de Francisco de Paula Santander a Carlos A. Torres. En Jaksic, I. y Posada Carbó, E. (eds) Liberalismo y Poder. Latinoamérica en el siglo XIX. Santiago de Chile: Fondo de Cultura Económica.

Samtleben J. (1986). Menschheitsglück und Gesetzgebungsexport. Zu Jeremy Benthams Wirkung in Lateinamerika. En Rabels Zeitschrift für ausländisches und internationales Privatrecht. Tubinga: J.C.B. Mohr (Paul Siebeck). 
Stoetzer, C. (1965). El influjo del utilitarismo inglés en la América Española. Revista de Estudios Políticos, Instituto de Estudios Políticos, Madrid, \# 143.

Wehner, F. (1969). Der Konflikt zwischen spanischer und liberaler Staatauffassung in Hispano-Amerika. Gedanken zu einem neuen Verständnis der Verfassungsentwicklung. En Verfassung und Recht in Übersee, 2. Jahrgang.

Wiarda, H. (1982). Law and Political Development in Latin America: Toward a Framework for Analysis. En H. J. Wiarda (ed.), Politics and Social Change in Latin America. The Distinct Tradition. The University of Massachusetts Press. 